\title{
Gemcitabine and taxanes in metastatic breast cancer: a systematic review
}

\author{
Vinay Gudena \\ Alberto J Montero \\ Stefan Glück \\ Division of Hematology/Oncology, \\ Braman Family Breast Cancer \\ Institute, UMSylvester Comprehensive \\ Cancer Center, University of Miami, \\ Miller School of Medicine, Miami, \\ FL, USA
}

\begin{abstract}
Incremental advances over the last two decades in the treatment of stage IV metastatic breast cancer (MBC) have resulted in significantly prolonging the average life expectancy. In 2008 , the estimated 5-year relative survival rate for MBC is $27 \%$ which compares favorably to rates in stage IV lung (3\%) and pancreatic cancers (1\%). Despite these advances, MBC remains an incurable disease, often associated with many symptoms and a decreased quality of life (QoL). Therefore, therapy goals in the treatment of MBC include prolonging both progressionfree survival and overall survival rates, while at the same time improving QoL by palliation of symptoms. Therefore, systemic chemotherapy ideally should not induce unnecessary toxicities. Once chemotherapy is indicated, a number of drugs and regimens are available but only a few offer both palliation of symptoms (responses to therapy) and overall survival benefit. The addition of novel biologic compounds to chemotherapy has been shown in phase III trials to improve all the above mentioned clinical outcomes in MBC. This review will discuss data supporting the use of gemcitabine/taxane combinations in the treatment of MBC.
\end{abstract}

Keywords: metastatic breast cancer, gemcitabine, taxanes

\section{Introduction}

Breast cancer remains a major public health problem for women. For 2008, in the US alone, there are estimated to be 180,460 new cases of breast cancer (Jemal et al 2008). Despite many advances in the treatment of breast cancer, it remains the second most common cause of cancer related mortality with 40,480 estimated deaths to occur this year alone (Jemal et al 2008). Although metastatic breast cancer (MBC) remains largely incurable, as is the case in most other advanced solid tumors, improvements in systemic chemotherapy and endocrine therapy have prolonged the average life expectancy of patients with MBC. Estimated 5-year relative survival rate for MBC is $27 \%$ (Jemal et al 2008). While not as good as the 5-year rates for stage IV testicular cancer $(70 \%)$, which in many cases is curable with systemic chemotherapy, in comparison with survival rates for lung $(3 \%)$ and pancreatic cancers $(1.7 \%), \mathrm{MBC}$ is a very treatable disease. In all patients regardless of HER-2/neu or hormone receptor status, chemotherapy remains an important component of the treatment of $\mathrm{MBC}$. Taxane-nucleoside analog combinations remain among the most active drugs for the treatment of $\mathrm{MBC}$ and have been shown in randomized phase III trials to be superior to single agent therapy in anthracycline-pretreated patients (O'Shaughnessy et al 2002; Albain et al 2008).

\section{Gemcitabine and rationale for combination over single-agent therapy in MBC}

The nucleoside analog gemcitabine (2', 2'-difluoro-deoxycytidine) is activated intracellularly by phosphorylation into di- and tri-phosphates by the enzyme deoxycytidine kinase. The tri phosphate form of gemcitabine competes with deoxycytidine 
triphosphate for incorporation into DNA and the di-phosphate form inhibits ribonucleotide reductase inhibiting DNA synthesis (Huang et al 1991). Once incorporated, it determines fragmentation with consequent cell death (Plunkett et al 1995). Gemcitabine has significant clinical activity in MBC and other solid tumors. Results from a recent phase III randomized trial demonstrated that gemcitabine in combination with paclitaxel as first-line therapy in MBC resulted in significant improvements in both median overall survival (OS) and time to progression (TTP) over that of paclitaxel alone (Albain et al 2008). Emerging data from other phase III trials have reported combination chemotherapy to be superior to single-agent as first- (O'Shaughnessy et al 2002; Beslija et al 2006; Melemed et al 2007) or second- or third-line therapy (Martin et al 2007).

This growing body of data with taxane and nucleoside analog combinations provides evidence refuting the notion that in $\mathrm{MBC}$ combination chemotherapeutic agents are not superior to sequential single agents. By contrast, the E1193 study (Sledge et al 2003), while showing significant improvements in overall response rates (ORR) and time to treatment failure with combining doxorubicin and paclitaxel, this did not translate into a significant difference in TTP and OS compared to either drug alone in a sequential fashion. This study was instrumental in changed practice early 2000s: the preferential treatment of MBC was single sequential use of drugs. This changed substantially when the combination of capecitabine and docetaxel (O'Shaughnessy et al 2002) and gemcitabine and paclitaxel (Albain et al 2008) were presented and published both demonstrating the advantage in response rate, progression-free survival (PFS) and OS. The latter study demonstrated considerably less adverse toxicities thus making it the preferred chemotherapy combination regimen for first-line MBC (Moinpour et al 2004).

However, despite the superiority of taxane-nucleoside analog combinations, there are several clinical situations where single agent therapy would be preferable to combination therapy in MBC which we will also discuss in this review.

\section{Rationale for non-anthracycline- containing regimens in MBC}

The widespread use of anthracyclines in the adjuvant setting, coupled with their cardiac and leukemogenic toxicities, has warranted the investigation of non-anthracycline alternatives. Non-anthracycline regimens are being studied in comparison with anthracycline-containing regimens in $\mathrm{MBC}$ and have been shown to be equal in efficacy. An example of one such study is the combination of capecitabine/paclitaxel (XP), which was compared with epirubicin/paclitaxel (EP). The results showed that the median PFS for EP was 11.8 months vs 12.3 months for XP $(p=n s)$. There was no difference in OS. Response rates were $41 \%$ for EP and $41.5 \%$ for XP, supporting the argument that non-anthracyclinecontaining regimens are at least as effective as anthracyclinecontaining regimens (Lück et al 2007). In this article we will review currently available data in the treatment of $\mathrm{MBC}$ with gemcitabine in combination with docetaxel, paclitaxel, or nab-paclitaxel. We will also review the preclinical evidence supporting the use of gemcitabine/taxane combinations in the clinical setting of MBC.

\section{Single-agent gemcitabine in MBC Phase II data}

Monotherapy with gemcitabine has been studied in many phase II studies with reported ORR between $14 \%$ and $37 \%$ as first-line therapy, and approximately $12 \%$ and $30 \%$ as second-line therapy after prior taxanes or anthracyclines (Silvestris et al 2008).

\section{Gemcitabine and taxanes}

Taxanes are a class of drugs that do not have overlapping side effects with gemcitabine and hence combinations of these agents with gemcitabine are feasible. Moreover, the addition of gemcitabine to taxanes in MBC patients, have led to improved ORR, and with paclitaxel demonstrated significant improvements in OS and TTP over paclitaxel alone.

\section{Gemcitabine and paclitaxel}

There are abundant pre-clinical data suggesting that the addition of paclitaxel to gemcitabine has an additive effect. By contrast, paclitaxel administered prior to gemcitabine significantly increases intracellular levels of 2',2'-difluorodeoxycytidine-5' -triphosphate, the active component of gemcitabine (Theodossiou et al 1998).

\section{Phase II studies}

Several phase II studies have been performed with gemcitabine/paclitaxel with reported ORR of $40 \%$ to $69 \%$, TTP of 8 to 9 months, and OS of approximately 12 months (Colomer et al 2004; Delfino et al 2004). Side effects were as expected and included neuropathy, myelosuppression and nausea, and vomiting (Colomer et al 2004; Delfino et al 2004). In the second-line setting, gemcitabine/ paclitaxel had a response rate of $45 \%$ to $55 \%$ (Murad et al 2001). A phase II study by Sánchez-Rovira used biweekly 
combination of doxorubicin at $30 \mathrm{mg} / \mathrm{m}^{2}$ (day 1), paclitaxel at $135 \mathrm{mg} / \mathrm{m}^{2}$ (day 2), and gemcitabine at $2500 \mathrm{mg} / \mathrm{m}^{2}$ (day 2 after paclitaxel) administered biweekly in a 28-day cycle for 6 cycles has been shown to have ORR of $83 \%$ with median TTP of 13.9 months as first-line therapy.

\section{Phase III registration trial}

Based on the response rates and safety data, a phase III study was conducted by Albain et al (2008) comparing gemcitabine/paclitaxel with paclitaxel alone. Ninety-eight centers in 19 countries participated in this trial and enrolled 529 patients with unresectable, locally recurrent, or measurable MBC. Patients were randomized to receive paclitaxel $\left(175 \mathrm{mg} / \mathrm{m}^{2}\right)$ on day 1 or paclitaxel $\left(175 \mathrm{mg} / \mathrm{m}^{2}\right)$ on day 1 with gemcitabine $\left(1250 \mathrm{mg} / \mathrm{m}^{2}\right)$ on days 1 and 8 every 21 days until disease progression. The primary endpoint was OS; secondary endpoints included TTP, ORR, and safety. The vast majority of enrolled patients had received prior adjuvant anthracyclines (96\% in each arm). All those who had received prior adjuvant taxanes or prior therapy for $\mathrm{MBC}$ were ineligible. Patients had a median age of 53 years (range 23-83), and most patients had metastatic (97\% per arm) and visceral disease (73\% per arm). Based on the interim results in May 2004, the US FDA approved the combination of gemcitabine/paclitaxel for first-line therapy in $\mathrm{MBC}$ in patients who had received prior anthracyclinebased adjuvant chemotherapy. The final results of this study were recently published. Demographic data in each were similar with a median age of 53 years. Gemcitabine was associated with significantly improved median OS (18.6 months vs 15.8 months; $\mathrm{p}=0.048)$, median TTP (6.1 months vs 4.0 months; $\mathrm{p}=0.00002)$, and ORR (41.4\% vs $11.5 \% \mathrm{p}=0.00002)$, compared with paclitaxel. Toxicity data shows that hematologic toxicities, especially grade 3-4 neutropenia was worse in the combination (47.9\% vs $11.5 \%$ ) and thrombocytopenia. However, febrile neutropenia rates were low in both arms $(\leq 5 \%)$. The combination had manageable non-hematological toxicities that were higher in the gemcitabine arm (fatigue, motor neuropathy, and elevation of transaminases). Dose reductions were $8 \%$ for gemcitabine and $8 \%$ for paclitaxel in the combination arm and $2 \%$ in the paclitaxel arm. Gemcitabine was omitted in $7 \%$ in the gemcitabine arm compared with less than $1 \%$ in paclitaxel arm. Fourteen percent in the paclitaxel arm went on to receive gemcitabine as part of subsequent therapy (Albain et al 2008). Another very important aspect was that quality of life (QoL) as measured by Rotterdam Symptom checklist Score was significantly improved with combination chemotherapy than with single agent paclitaxel (Moinpour et al 2004).

\section{Gemcitabine and docetaxel Phase II studies}

Published phase II data with gemcitabine and docetaxel report objective response rates of $59 \%$ to $79 \%$, and median TTP between 8.5 and 11 months in the first-line setting. In second- and third-line settings published objective response rates were as expected lower (36\%-54\%) with median TTP of 7 to 8 months (Kornek et al 2002; Mavroudis et al 2004; Pelegri et al 2005).

\section{Phase III study}

The combination of gemcitabine and docetaxel was tested in a phase III trial by Chan et al (2005). Patients with MBC who had received prior anthracyclines either in the adjuvant or metastatic setting were randomized to receive either gemcitabine $1000 \mathrm{mg} / \mathrm{m}^{2}$ (days 1 and 8) plus docetaxel $75 \mathrm{mg} / \mathrm{m}^{2}$ (day 1) [GD] or capecitabine $1250 \mathrm{mg} / \mathrm{m}^{2}$ twice daily (days 1-14) plus docetaxel $75 \mathrm{mg} / \mathrm{m}^{2}$ (day 1 ) every 3 weeks [XD]. The primary endpoint of this randomized trial was PFS. Secondary endpoints included: safety, QoL, OS, and ORR. Patients were stratified based on: first- or second-line therapy for metastatic disease, presence or absence of visceral metastasis, and prior taxane therapy. Arms were well balanced; median age was 55 years; $86 \%$ had visceral involvement; $81 \%$ had $\geq 2$ metastatic sites; $67 \%$ were ER/PR+; 17\% were HER2 over-expressed; $17 \%$ received prior taxane; 34\% received prior chemotherapy for metastatic disease. There was no statistically significant difference in both the arms for efficacy or adverse effects. PFS was 8.2 months in both arms and ORR was $32 \%$. There was also no difference whether the drugs were used in first- or second-line settings. Hematological toxicities were similar including febrile neutropenia ( $8 \%$ vs 13\%), grade 3-4 neutropenia (85\% vs 82\%). Grade 3-4 thrombocytopenia was more common with GD (11\% vs 3\%). Overall, there were significantly greater grade 3-4 non-hematologic toxicities with XD than GD including: diarrhea (17\% vs 7\%), hand-foot syndrome (26\% vs $0 \%)$, and mucositis (17\% vs $4 \%$ ), respectively. It is likely that the dose of capecitabine explains the excess of non-hematologic toxicities with XD in this trial. Although the approved dose of capecitabine is $1250 \mathrm{mg} / \mathrm{m}^{2}$, it is quite rarely used in clinical practice at these doses, particularly in the US (Chan et al 2005). Rossi et al (2007) showed that lower and better-tolerated doses of capecitabine show similar activity to the FDA-approved dose of $2500 \mathrm{mg} / \mathrm{m}^{2}$ given daily for 2 of 3 weeks. 
Table I Phase III randomized trials with gemcitabine/taxane combinations in metastatic breast cancer (MBC)

\begin{tabular}{|c|c|c|c|c|c|c|}
\hline Treatment & Patient characteristics & \# Patients & $\begin{array}{l}\text { Overall } \\
\text { response rate }\end{array}$ & $\begin{array}{l}\text { Median overall } \\
\text { survival (months) }\end{array}$ & $\begin{array}{l}\text { Progression } \\
\text { (months) }\end{array}$ & Reference \\
\hline $\begin{array}{l}\text { Gemcitabine } \\
\text { I } 250 \mathrm{mg} / \mathrm{m}^{2} \\
\text { (d I,8) plus paclitaxel } \\
175 \mathrm{mg} / \mathrm{m}^{2}(\mathrm{~d} \mathrm{I}) \\
\text { vs }\end{array}$ & $\begin{array}{l}\text { No prior chemotherapy } \\
\text { for MBC; no prior } \\
\text { taxanes; prior adjuvant } \\
\text { anthracyclines }(95 \%) ; \\
\text { pisceral disease }(73 \%) ; \geqslant 3 \\
\text { sites of metastases }(43 \%) ; \\
\text { HER-2 status of patients } \\
\text { not reported }\end{array}$ & 266 & $41.4 \%^{\mathrm{a}}$ & $18.6^{\mathrm{b}}$ & $\begin{array}{l}\text { TTP } \\
6.1^{c}\end{array}$ & $\begin{array}{l}\text { Albain et al } \\
2008\end{array}$ \\
\hline $\begin{array}{l}\text { Paclitaxel } 175 \mathrm{mg} / \mathrm{m}^{2} \\
\text { (d I)every } 21 \text { days }\end{array}$ & & 263 & $26.2 \%$ & 15.8 & 4.0 & \\
\hline $\begin{array}{l}\text { Gemcitabine } \\
1000 \mathrm{mg} / \mathrm{m}^{2}(\mathrm{~d} \mathrm{l}, 8) \\
\text { plus docetaxel } \\
75 \mathrm{mg} / \mathrm{m}^{2}(\mathrm{~d} \mathrm{l}) \\
\text { vs } \\
\text { Capecitabine } \\
1250 \mathrm{mg} / \mathrm{m}^{2} \text { bid } \\
(\mathrm{d} \mathrm{I}-14) \text { plus docetaxel } \\
75 \mathrm{mg} / \mathrm{m}^{2}(\mathrm{~d} \mathrm{I}) \\
\text { every } 2 \mathrm{I} \text { days }\end{array}$ & $\begin{array}{l}\text { Prior adjuvant/neoad- } \\
\text { juvant and/or first-line } \\
\text { chemotherapy for MBC } \\
\text { allowed:Adj/neoadj }(64 \%) ; \\
\text { MBC (22\%); Both ( } 13 \%) ; \\
\text { prior anthracyclines (70\%); } \\
\text { prior adj/neoadj taxane } \\
\text { allowed if } \geq 6 \text { months } \\
\text { since completion ( } 10 \%) ; \\
\geq 3 \text { sites of metastases } \\
\text { (48\%); visceral disease } \\
(84 \%) ; \text { HER-2+ (I7\%); } \\
\text { HER-2 unknown (35\%) }\end{array}$ & 153 & $32 \%$ & 19.3 & $\begin{array}{l}\text { months } \\
\text { Median PFS } 8 \text { months } \\
\text { I2-month PFS 24\% } \\
\text { Median PFS } 8 \text { months } \\
\text { I2-month PFS 30\% }\end{array}$ & $\begin{array}{l}\text { Chan et al } \\
2005\end{array}$ \\
\hline
\end{tabular}

${ }^{\mathrm{a}} \mathrm{p}=0.0002 ;{ }^{\mathrm{b}} \mathrm{p}=0.0489 ;{ }^{\mathrm{c}} \mathrm{p}<0.0002$.

Abbreviations: $\mathrm{MBC}$, metastatic breast cancer; PFS, progression-free survival.

A QoL analysis of the study by Chan et al (2005) was conducted by Fumoleau et al (2006) using the Rotterdam Symptom Checklist (RSCL). No statistical differences between arms were seen for any of the RSCL dimensions ( $p>0.05$ at all cycles). By cycle 3 , more GD patients reported tiredness ( $58 \%$ vs $47 \%$ ), lack of energy ( $45 \%$ vs $38 \%$ ), back pain $(19 \%$ vs $9 \%)$, and by cycle 2 , alopecia $(76 \%$ vs $66 \%)$. By cycle 1, more XD patients reported tingling hands/feet (15\% vs 7\%) and burning/sore eyes (14\% vs 3\%) (Fumoleau et al 2006). In a phase III study by O'Shaughnessy et al (2002), $\mathrm{XD}$ was found to be superior to single-agent docetaxel in firstline MBC. Based on the study by Chan et al (2005), GD was found to have similar efficacy compared with capecitabine/ docetaxel, with fewer non-hematologic toxicities.

\section{Gemcitabine/paclitaxel (GT) vs gemcitabine/docetaxel (GD)}

A randomized phase II trial was conducted to assess the efficacy and safety of GT vs GD combination regimens in patients previously treated for MBC. GT (G $1250 \mathrm{mg} / \mathrm{m}^{2}$ iv on days 1 and 8 plus $P 175 \mathrm{mg} / \mathrm{m}^{2}$ iv on day 1 ) or GD (G $1000 \mathrm{mg} / \mathrm{m}^{2}$ iv on days 1 and 8 plus D $75 \mathrm{mg} / \mathrm{m}^{2}$ iv on day 1) every 21 days.
Only 25 patients were randomized due to slow accrual and 23 were analyzed for response. Overall response rate was $39 \%$ (95\% CI $20 \%-61 \%)$ for the GT group and $40 \%$ (95\% CI $21 \%-61 \%$ ) for the GD group. The median number of cycles administered was 6.5 in the GT group and 6.0 in the GD group. More febrile neutropenia was seen in 4 patients (16\%) in GD arm and more neuropathy was seen GT arm 2 patients (8\%). The authors concluded that GT and GD combination regimens are both efficacious in the treatment of MBC, with similar response rates and manageable toxicity profiles.

\section{Gemcitabine and nab-paclitaxel}

Nanoparticle albumin-bound paclitaxel (nab-paclitaxel, ABI-007, Abraxane ${ }^{\circledR}$ ) is a solvent-free formulation. Nabpaclitaxel has several practical advantages over standard formulation paclitaxel including a lack of hypersensitivity reactions, no need for special tubing for infusion, and shorter infusion time. Phase I trials demonstrated that the maximum tolerated dose of nab-paclitaxel was $300 \mathrm{mg} / \mathrm{m}^{2}$ on day 1 in combination with gemcitabine $1000 \mathrm{mg} / \mathrm{m}^{2}$ on days 1,8 on an every 21-day schedule (Stinchcombe et al 2008). Based on these data, phase II studies have been conducted in many tumor types including MBC. 


\section{Phase II data}

A phase II study of nab-paclitaxel in combination with gemcitabine in MBC was conducted by the North Central Cancer Treatment Group. Patients were treated with nab-paclitaxel $125 \mathrm{mg} / \mathrm{m}^{2}$ followed by gemcitabine $1000 \mathrm{mg} / \mathrm{m}^{2}$ days 1 and 8 of a 21-day cycle. The primary end point of this trial was overall response rate. Preliminary results were presented to ASCO 2007 (Roy et al 2007). Fifty patients with $\mathrm{MBC}$ were enrolled with approximately $80 \%$ having visceral involvement. Twenty-five patients (50\%) had received prior adjuvant chemotherapy, including $15(30 \%)$ prior taxanes. Forty-one patients discontinued treatment, due to progression (41\%), patient refusal (27\%), adverse events $(17 \%)$, and alternative treatments (7\%). The study reported an ORR of 48\%: 4 complete response (CR) and 20 partial response (PR). The median duration of response and median PFS were 6.6 months and 7.9 months, respectively. The most common grade 3-4 adverse events included: neutropenia $(52 \%)$, fatigue (26\%), anemia (14\%), dyspnea (14\%), and thrombocytopenia (12\%). This study therefore demonstrated that nab-paclitaxel/gemcitabine is a very active and well tolerated regimen in the treatment of MBC (Moreno-Aspitia and Perez 2005; Roy et al 2007).

\section{Gemcitabine, nab-paclitaxel, and bevacizumab}

Lobo et al (2007) reviewed a single-institution experience, evaluating safety and preliminary evidence of activity with the use of nab-paclitaxel and bevacizumab with and without gemcitabine in heavily pretreated HER-2/neu-negative in 6 women with $\mathrm{MBC}$. The investigators assessed response independently of treating physician. RECIST criteria were used. Three patients received nab-paclitaxel and bevacizumab at the following doses: nab-P $100 \mathrm{mg} / \mathrm{m}^{2}$, B $10 \mathrm{mg} / \mathrm{kg}$ every 2 weeks, and 3 patients also received gemcitabine at $1000 \mathrm{mg} / \mathrm{m}^{2}$; all 3 drugs were given every 2 weeks. Median age was 51 (range, 34-69). Two patients had hormonereceptor positive disease and 3 had triple negative breast cancer (ER/PR/Her-2-negative). The median prior number of regimens was 3 (range, 2-7). Five patients had been previously treated with a taxane -1 received both paclitaxel and docetaxel, and 4 docetaxel only. A median of 16 weeks of treatment was administered (range $8+$ to $32+$ ). First-cycle grade 3-4 toxicity was seen in only 1 patient who had a baseline grade 2 thrombocytopenia which progressed to grade 3 . The thrombocytopenia resolved without transfusion or hemorrhagic complication. Other treatment-related toxicities were as follows: grade 2 peripheral neuropathy $(n=1)$; grade 2 nausea $(\mathrm{n}=1)$. One patient had a blood pressure of 210/140 mmHg while non-compliant with her prior antihypertensive therapy. Two patients had confirmed PR and 4 patients had stable disease (Lobo et al 2007).

Gluck et al (2008) reported preliminary data of the first study to examine the efficacy of combination therapy with nab-paclitaxel, bevacizumab, and gemcitabine as first-line treatment for patients with MBC. Patients ( $\geq 18$ years with untreated HER2-negative MBC or metastases diagnosed $\geq 6$ months after primary systemic treatment) received gemcitabine $1500 \mathrm{mg} / \mathrm{m}^{2}$, nab-paclitaxel $150 \mathrm{mg} / \mathrm{m}^{2}$, and bevacizumab $10 \mathrm{mg} / \mathrm{kg}$ (each administered intravenously over 30 minutes) on days 1 and 15 of 28-day cycles. Cycles were repeated for the duration of therapy. PFS is the primary endpoint; secondary endpoints include rates of CR or PR, OS, safety, and toxicity. So far, 22 of 30 patients (21 female; mean age, 54 years) have been enrolled, of whom 17 were evaluated for efficacy (received $\geq 2$ cycles), 22 for safety. All patients were HER2-negative; $80 \%$ were ER+, and 58\% were PR+. Fourteen (76\%) patients achieved PR, and $1(6 \%)$ patient had stable disease. All adverse events were grade 1 or 2 , and the most commonly reported side effects were alopecia $(62 \%)$ and fatigue (38\%) and rash $(23 \%)$. Three patients were hospitalized because of port site infection $(n=2)$ and hematologic toxicity with neutropenic fever $(n=1)$. This interim analysis demonstrates a very high ORR to first-line combination therapy with nab-paclitaxel, bevacizumab, and gemcitabine in patients with MBC. Despite the small sample size, these data suggest that this regimen may represent an important new option for the first-line treatment of patients with MBC (Gluck et al 2008).

\section{Gemcitabine/paclitaxel/ trastuzumab}

Trastuzumab in combination with chemotherapy in HER-2/ neu over-expressing breast cancers improves OS (Slamon et al 2001). A clinical trial investigated the combinationof paclitaxel $80 \mathrm{mg} / \mathrm{m}^{2} /$ week, gemcitabine $1000 \mathrm{mg} / \mathrm{m}^{2}$ every 2 weeks, and trastuzumab $4 \mathrm{mg} / \mathrm{kg}$ loading dose and then $2 \mathrm{mg} / \mathrm{kg} /$ week for a total of 12 weeks in MBC. This study reported an ORR of $52.5 \% ; 25 \%$ had stable disease and $20 \%$ had progressive disease. Median duration of response was 14 months. Median time to progression is 13.7 months, whereas median survival was not reached (Fountzilas et al 2004).

\section{Scheduling of gemcitabine/taxanes}

The optimal biologic dosing schedule for taxanes and nucleoside analogues is still unclear. Results from several 
preclinical studies have suggested that the administration of paclitaxel prior to gemcitabine results in an increase in the 2',2'-difluoro-deoxycytidine-5' triphosphate, the active metabolite of gemcitabine (Kroep et al 2000). In another preclinical study performed in breast cancer cell lines it was shown that when gemcitabine was administered 48 hours after doxorubicin/paclitaxel combination, there was synergism. The explanation was that doxorubicin/paclitaxel causes G2-M phase block and that the cells re-enter the cell-cycle 8 hours after paclitaxel administration, and as they enter G-S phase, gemcitabine exerts its cytotoxic activity. Based on these preclinical observations, paclitaxel followed by gemcitabine is the most commonly used sequence (Zoli et al 1999).

The majority of gemcitabine/taxane regimens in $\mathrm{MBC}$ use every-3-week cycles. However, it had been shown that if chemotherapy could be given more frequently at the same or lower dose, it would lead to higher responses and greater cell death (Fornier and Norton 2005). In the adjuvant setting, it is widely accepted that every-2-week dose dense chemotherapy with filgrastim support improves disease-free survival and improved tolerability, with less neutropenia (Citron et al 2003). A phase II study was conducted to evaluate gemcitabine $\left(2500 \mathrm{mg} / \mathrm{m}^{2}\right.$ day 1$)$ and paclitaxel $\left(150 \mathrm{mg} / \mathrm{m}^{2}\right.$ on day 1$)$ with or without prophylactic filgrastim (G-CSF). Forty-three patients were enrolled. An ORR of $78 \%$ was observed and 11 patients had CR (26\%) and, most interestingly, G-CSF was not required for this combination (Colomer et al 2004). A lower response rate $(59 \%)$ was obtained when the dose of gemcitabine was reduced to $1500 \mathrm{mg} / \mathrm{m}^{2}$ in combination with docetaxel in a phase II study, suggesting that a lower dose of gemcitabine every 2 weeks may be too low for an effective anti-tumor effect (Pelegri et al 2002).

\section{Alternative dosing of gemcitabinel taxanes}

A phase II randomized trial comparing three regimens was conducted by Khoo et al (2004). The study compared paclitaxel given on days 1 and 8 with the standard regimen of every 3 weeks and with docetaxel given on days 1 and 8 every 3 weeks. A total of 8 cycles were administered and prophylactic G-CSF was not routinely allowed. Efficacy was similar between each gemcitabine/taxane combination and toxicity was similar for paclitaxel given weekly or once every 3 weeks. Anemia, neutropenia, febrile neutropenia, infectious episodes, and diarrhea were more pronounced in the gemcitabine/docetaxel combination and were associated with higher use of blood transfusions, G-CSF, and antibiotics (Khoo et al 2004).

\section{Single-agent sequential therapy vs combination therapy: when is one drug enough in MBC?}

Despite emerging evidence that combination chemotherapy, including here a combination of cytotoxic chemotherapy with monoclonal antibodies, eg, bevacizumab and trastuzumab, there are situations when single-agent sequential therapy would be more appropriate in $\mathrm{MBC}$ and clearly 2 or 3 drugs are "too much": (i) poor performance status patients and/or elderly or non-elderly patients with multiple co-morbidities that would increase the likelihood of adverse toxicities with combination chemotherapy; (ii) patients with rather minimal signs or symptoms and/or with few metastasitc sites, who are thus asymptomatic from their disease. Consequently, in these situations single sequential drug use would have less propensity for adverse toxicities and consequently would help to maintain improved QoL in patients as long as possible.

Moving specifically to combinations of biologic and targeted agents to gemcitabine-taxane doublets in the treatment of HER-2 unamplified MBC, although many studies are underway only the addition of bevacizumab to weekly paclitaxel has been shown to significantly improve PFS. In the ECOG 2100 randomized phase III trial the addition of bevacizumab to weekly paclitaxel (3 out of 4 weeks) improved PFS by almost 6 months (11.8 vs 5.9 months; $\mathrm{p}<0.001$ ) with no difference in OS (Miller et al 2007). Many other studies are ongoing, such as the combination of bevacizumab and docetaxel, the combination of paclitaxel, gemcitabine, and bevacizumab, and many others. At this point no phase III data are available to indicate whether the addition of gemcitabine to a bevacizumab/taxane doublet as first-line therapy for HER-2 unamplified MBC results in superior clinical outcomes. Therefore, the treating medical oncologist should have an open discussion with the patient to determine the goals of therapy and the limitations of the current clinical data. Nevertheless, there are certain situations where it may be reasonable to recommend combination bevacizumab/taxane chemotherapy with or without gemcitabine for first-line treatment of HER-2 unamplified MBC: (i) patients with more metastatic tumor burden; (ii) symptomatic patients; (iii) triple negative disease; (iv) younger age; (v) other poor prognostic factors, eg, $>5$ circulating tumor cells, short interval between adjuvant therapy, and diagnosis of MBC. Subsequent lines of treatment would probably be 
equivalently treated with a single sequential approach as in the past unless new data emerge.

\section{Conclusions}

Despite recent advances in chemotherapeutic agents for $\mathrm{MBC}$, it is still an incurable disease and the purpose of chemotherapy remains that of relieving symptoms and improving QoL. It is also widely realized that response rates do sometimes correlate with survival and hence rational drug combinations for effective cytotoxicity with good tolerability are essential for the management of MBC. The combination of gemcitabine and taxanes is an effective regimen that is well tolerated with good response rates, as illustrated in this review. This is all the more true in anthracycline-resistant or anthracycline-refractory cases. The combination of gemcitabine/paclitaxel has been approved by the FDA for $\mathrm{MBC}$ and the other two combinations (gemcitabine/docetaxel and gemcitabine/nab-paclitaxel) are also reasonable alternatives given the phase II data reviewed in this article.

We can conclude that a gemcitabine/taxane combination is very promising and in one study has shown an overall survival advantage. Other gemcitabine/taxane combinations with agents targeting the vascular endothelial growth factor receptor need to be further explored in phase III trials. We can also conclude that the era of single-agent sequential therapy for MBC is over for many patients, based on several studies showing superiority. It remains to be seen in what sequence these drug combinations used in first-, second-, third-, and fourth-line settings offers the best potential for time to progression, response rates, and survival while preserving QoL.

\section{Disclosures}

AJM is on the speakers' bureau for Eli Lilly, Abraxis Oncology, and Veridex. SG is on the speakers' bureau for, and has received research support from, Eli Lilly, Abraxis Oncology, and Genentech. VG has no conflicts to disclose.

\section{References}

Albain KS, Nag SM, Calderillo-Ruiz G, et al. 2008. Gemcitabine plus paclitaxel versus paclitaxel monotherapy in patients with metastatic breast cancer and prior anthracycline treatment. J Clin Oncol, 26:3950-7.

Beslija S, Obralic N, Basic H, et al. 2006. Randomized trial of sequence vs combination of capecitabine $(\mathrm{X})$ and docetaxel $(\mathrm{T})$ : XT vs T followed by $\mathrm{X}$ after progression as first-line therapy for patients (pts) with metastatic breast cancer (MBC). J Clin Oncol (Meeting Abstracts), $24: 571$.

Chan S, Romieu G, Houber J et al. 2005. Gemcitabine plus docetaxel (GD) versus capecitabine plus docetaxel (CD) for anthracycline-pretreated metastatic breast cancer (MBC) patients (pts): Results of a European phase III study. J Clin Oncol, 2005 ASCO Annu Meeting Proc 23(June 1 Suppl):581.
Citron ML, Berry DA, Cirrincione C, et al. 2003. Randomized trial of dose-dense versus conventionally scheduled and sequential versus concurrent combination chemotherapy as postoperative adjuvant treatment of node-positive primary breast cancer: first report of Intergroup Trial C9741/Cancer and Leukemia Group B Trial 9741. J Clin Oncol, 21:1431-9.

Colomer R, Llombart-Cussac A, Lluch A, et al. 2004. Biweekly paclitaxel plus gemcitabine in advanced breast cancer: phase II trial and predictive value of HER2 extracellular domain. Ann Oncol, 15:201-6.

Delfino C, Caccia G, Gonzales LR, et al. 2004. Gemcitabine plus paclitaxel as first-line chemotherapy for patients with advanced breast cancer. Oncology, 66:18-23.

Fornier M, Norton L. 2005. Dose-dense adjuvant chemotherapy for primary breast cancer. Breast Cancer Res, 7:64-9.

Fountzilas G, Christodoulou C, Tsavdaridis D, et al. 2004. Paclitaxel and gemcitabine, as first-line chemotherapy, combined with trastuzumab in patients with advanced breast cancer: a phase II study conducted by the Hellenic Cooperative Oncology Group (HeCOG). Cancer Invest, 22:655-62.

Fumoleau P, Romieu G, Chan S, et al. 2006. Impact of symptoms and toxicity on quality of life: Exploratory analysis of gemcitabine plus docetaxel vs capecitabine plus docetaxel in metastatic breast cancer. J Clin Oncol, 2006 ASCO Annu Meeting Proc 24(June 20 Suppl):682.

Gluck S, Lobo S, Reis I, et al. 2008. Phase II study of nab-paclitaxel, bevacizumab, and gemcitabine for first-line therapy of patients with HER2-negative metastatic breast cancer (MBC). J Clin Oncol, 26(May 20 Suppl):Abstr 1089.

Huang P, Chubb S, Hertel LW, et al. 1991. Action of 2',2'-difluorodeoxycytidine on DNA synthesis. Cancer Res, 51:6110-17.

Jemal A, Siegel R, Ward E, et al. 2008. Cancer statistics. CA Cancer J Clin, 58:71-96.

Khoo K-S MZ, Srimuninnimit V, Jiang ZF, et al. 2004. Randomized phase II trial of three gemcitabine (GEM)-taxane combinations in metastatic breast cancer (MBC). J Clin Oncol, 2004 ASCO Annu Meeting Proc 22(July 15 Suppl):710.

Kornek GV, Haider K, Kwasny W, et al. 2002. Treatment of advanced breast cancer with docetaxel and gemcitabine with and without human granulocyte colony-stimulating factor. Clin Cancer Res, 8:1051-6.

Kroep JR, Giaccone G, Tolis C, et al. 2000. Sequence dependent effect of paclitaxel on gemcitabine metabolism in relation to cell cycle and cytotoxicity in non-small-cell lung cancer cell lines. $\mathrm{Br} J$ Cancer, 83:1069-76.

Lobo C, Lopes G, Silva O, Gluck S. 2007. Paclitaxel albumin-bound particles (abraxane) in combination with bevacizumab with or without gemcitabine: early experience at the University of Miami/Braman Family Breast Cancer Institute. Biomed Pharmacother, 61:531-3.

Lück H-J dBA, Schrader I, Huober J, et al. 2007. Final results of the AGO Breast Cancer Study Group MAMMA-3 Trial: first-line capecitabine + paclitaxel vs epirubicin + paclitaxel for high-risk metastatic breast cancer. San Antonio Breast Cancer Symposium (SABCS). San Antonio.

Martin M, Ruiz A, Munoz M, et al. 2007. Gemcitabine plus vinorelbine versus vinorelbine monotherapy in patients with metastatic breast cancer previously treated with anthracyclines and taxanes: final results of the phase III Spanish Breast Cancer Research Group (GEICAM) trial. Lancet Oncol, 8:219-25.

Mavroudis D, Malamos N, Polyzos A, et al. 2004. Front-line chemotherapy with docetaxel and gemcitabine administered every two weeks in patients with metastatic breast cancer: a multicenter phase II study. Oncology, 67:250-6.

Miller K, Wang M, Gralow J, et al. 2007. Paclitaxel plus bevacizumab versus paclitaxel alone for metastatic breast cancer. $N$ Engl J Med, 357:2666-76.

Moinpour C WJ, Donaldson G, Liepa A, et al. 2004. Gemcitabine plus paclitaxel (GT) versus paclitaxel (T) as first-line treatment for anthracycline pre-treated metastatic breast cancer (MBC): Quality of life (QoL) and pain palliation results from the global phase III study. J Clin Oncol, 2004 ASCO Annu Meeting Proc 22(July 15 Suppl):621. 
Moreno-Aspitia A, Perez EA. 2005. North Central Cancer Treatment Group N0531. Phase II trial of weekly albumin-bound paclitaxel (ABI-007; Abraxane) in combination with gemcitabine in patients with metastatic breast cancer. Clin Breast Cancer, 6:361-4.

Murad AM, Guimaraes RC, Aragao BC, et al. 2001. Phase II trial of the use of paclitaxel and gemcitabine as a salvage treatment in metastatic breast cancer. Am J Clin Oncol, 24:264-8.

O'Shaughnessy J, Miles D, Vukelja S, et al. 2002. Superior survival with capecitabine plus docetaxel combination therapy in anthracyclinepretreated patients with advanced breast cancer: phase III trial results. J Clin Oncol, 20:2812-23.

Pelegri A, Calvo L, Mayordomo JI, et al. 2002. Gemcitabine and docetaxel given every 2 weeks as first-line therapy for metastatic breast cancer (MBC): results of a GEICAM phase II study. Proc Am Soc Clin Oncol, 21:Abstr 1950.

Pelegri A, Calvo L, Anton A, et al. 2005. Docetaxel/gemcitabine administered every other week as first-line treatment for metastatic breast cancer: final results of a phase II trial. Clin Breast Cancer, 6:433-8.

Plunkett W, Huang P, Xu YZ, et al. 1995. Gemcitabine: metabolism, mechanisms of action, and self-potentiation. Semin Oncol, 22(4 Suppl 11):3-10.

Rossi D, Alessandroni P, Catalano V, et al. 2007; Safety profile and activity of lower capecitabine dose in patients with metastatic breast cancer. Clin Breast Cancer, 7:857-60.
Roy V, LaPlant BR, Gross GG, et al. 2007. NCCTG phase II trial N0531 of weekly nab-paclitaxel in combination with gemcitabine in patients with metastatic breast cancer. Proc Am Soc Clin Oncol, 25(Suppl 18): A1048.

Silvestris N, Cinieri S, La Torre I, et al. 2008. Role of gemcitabine in metastatic breast cancer patients: A short review. Breast, 17:220-6.

Slamon DJ, Leyland-Jones B, Shak S, et al. 2001; Use of chemotherapy plus a monoclonal antibody against HER2 for metastatic breast cancer that overexpresses HER2. N Engl J Med, 344:783-92.

Sledge GW, Neuberg D, Bernardo P, et al. 2003. Phase III trial of doxorubicin, paclitaxel, and the combination of doxorubicin and paclitaxel as front-line chemotherapy for metastatic breast cancer: an intergroup trial (E1193). J Clin Oncol, 21:588-92.

Stinchcombe TE, Socinski MA, Lee CB, et al. 2008. Phase I trial of nanoparticle albumin-bound paclitaxel in combination with gemcitabine in patients with thoracic malignancies. J Thorac Oncol, 3:521-6.

Theodossiou C, Cook JA, Fisher J, et al.1998. Interaction of gemcitabine with paclitaxel and cisplatin in human tumor cell lines. Int $J$ Oncol, 12:825-32.

Zoli W, Ricotti L, Barzanti F, et al. 1999; Schedule-dependent interaction of doxorubicin, paclitaxel and gemcitabine in human breast cancer cell lines. Int J Cancer, 80:413-6. 